\section{THE STUDENTS' POCKET PRESCRIBER AND GUIDE TO PRESCRIPTION WRITING}

By David Mitchell Macdonald, M.D., D.P.H., F.R.C.P.E. 12th Edition. Pp. 348. E. and 'S. Livingstone, Ltd. Edinburgh. 1945. Price 4s.

A useful, handy little volume, most moderately priced. The first edition appeared as long ago as 1882 , since which eighteen new editions or reprints have been issuedsufficient testimony of its continued and well-deserved popularity. For the benefit of those unfamiliar with this manual attention may briefly be called to its contents, which include among others incompatibilities, synonyms for drugs, prescriptions arranged alphabetically by indications, N.H.I. and N.W.F. formulae, proprietary preparations with names of manufacturers, posological table, diet in various diseases, vitamins, dangerous drug acts, and vocabulary of Latin words and phrases.

\section{AIDS TO FEVERS FOR NURSES}

By Joyce M. Watson, S.R.N., S.R.F.N., D.N. Foreword by H. Stanley Banks, M.A., M.D., M.R.C.P., D.P.H. Second Edition. Pp. 362 . Baillière, Tindall and Cox. London. 1945. Price 45.

The reviewer agrees with the Medical Superintendent of the Park Fever Hospital, who describes this manual as a "veritable mine of information on fevers which should be of the highest value not only to the trainee but to the qualified nurse," but is inclined to think that almost all the information contained in its 362 pages could also usefully be read by medical students. While the price is certainly in sympathy with the descriptive name of this useful series, its size has outgrown the modest name "Nurses' Aids Series." The presentation, lucid and up to date, is essentially practical, emphasis throughout being laid on what the nurse should observe and report. It is noted that the term "German Measles" is not used, except in the Appendix, and it is presumed that the Fever Nurse is expected to employ the Latin terminology. It is felt that the incubation period allotted to gonorrhoea (three to five days) errs on the side of underestimation.

\section{ARTIFICIAL RESPIRATION EXPLAINED}

By Frank C. Eve, M.D., F.R.C.P. Pp. 76. Mls. 32. E. and S. Livingstone, Ltd. Edinburgh. 1946. Price 3s.

"Artificial respiration," writes the author in his foreword, "has hitherto been dealt with only in small corners of books on First Aid. In the last few years, our knowledge of this important subject has increased so much that it now demands a little book all to itself." Dr. Eve's "little book" can be warmly recommended as being authoritative, up to date, lucidly written, clearly printed, well illustrated, and modestly priced. The first four chapters explain natural and artificial respiration and asphyxia, while Chapter V contains brief instructions in the chief methods of artificial respiration. The rocking method is described as the most efficient, both for ventilation and circulation. Manual methods are discussed which can be undertaken in confined spaces such as rescue boats. The index has been carefully compiled.

HERMAPHR ODI TOS: THE HUMAN INTERSEX

By A. P. Cawadias, O.B.E., M.D., F.R.C.P. Second Edition. Pp. 8I. Ills. I4. William Heinemann. Medical Books, Ltd. London. 1946. Price I5s. net.

Full of scholarship and fascination, this expanded version of Dr. Cawadias' Thomas Vicary Lecture, delivered before the Royal College of Surgeons of England in 1940, is thoroughly recommended as a happy blend of historicap lore with modern endocrinology. First published if July 1943, in this second edition, dated March 1946, the्] chapter on the physiopathology of intersexuality has been re-written "so as to make clearer the existence of two great physiopathological classes of intersexuality, the dee constitutional and the endocrine intersexualities-a dise tinction important from both the clinical and the therapeutic standpoints." The clinical chapters have als been rewritten "so as to clarify the various forms in which. intersexuality manifests itself to the clinician." The illustrations, while interesting and instructive, are somes what crudely reproduced. But the author prefers thes classical figures to photographs of his own patients published with a mask as this "distracts from the most important morphological element, the facies." A full and painstakingly compiled bibliography enhances the value of this book, but the index is disappointingly inadequate

\section{PATHOLOGY AND THERAPY OF RHEUMATI $\vec{g}$} FEVER

By LeOPOLD Lichtwitz, M.D. Wm. Heinemann, Londo超 1944. Price 2 Is.

The title of this work, viz.: Pathology and Therapy of Rheumatic Fever, would not seem to be well chosen becauge this particular malady only occupies a comparatively small proportion of the letterpress, the bulk of the space being taken up with a description of all the conditions to which the adjective "rheumatic" has ever been applief? In spite of this criticism, however, a reading of the boof will be of interest and of value for it provides a Bery comprehensive, although perhaps not very crittity review of all so-called "rheumatic" diseases. In addifiog there is provided a most detailed account of all the varibus remedies which have ever been tried, but unfortunater with little indication of what particular measures will found really efficacious. The author is an ardent fapporter of the allergic view of the cause of the rheumatis infection but unfortunately his treatment of this melly of the subject lacks the comprehensiveness of the sectons dealing with symptomatology and treatment, verg little space being devoted to a discussion of the microbse and virus views of aetiology. It should be mentioned that there is a very full bibliography and a good inde so that it will form a serviceable work of reference. form, type and excellence of the illustrations the boog reflects great credit on the publishers.

\section{MATERIA MEDICA, PHARMACOLOGY, AND THERAPEUTICS}

By William Hale-White, K.B.E., M.D., LL.D., revised by A. H. Douthwaite, M.D., F.R.C.P. 26th Edition (I 3oth thousand). J. \& A. Churchill, Ltd. Londo 1944. Price I4s.

This well-known and valuable work is again forwara with a new edition, revised up-to-date, and increased in size to meet the newer research. Thus, of just over 500 pages (plus 25 for index), 38 pages are now absorbed for Hormones, 19 for Sulphonamides, 9 for Antitoxic Sef and Toxins, 6 for Vaccines, 8 for Anti-Coagulants, and 3 for Penicillin. The rest of the book is on the same high standard of information as to constitution, action, arf therapeutic application of the multifarious drugs and thef application. It is therefore strongly recommended to students and practitioners of medicine in the importaf matter of keeping abreast of advances in the practice of their profession, guided by competent authorities. There seems to be a convention to keep the name MacLeares Powder out of textbooks and their indexes, but surelycit is useful to know the composition of the powders whis 